\title{
CORRESPONDENCE
}

We welcome letters to the Editor concerning articles which have recently been published. Such letters will be subject to the usual stages of selection and editing; where appropriate the authors of the original article will be offered the opportunity to reply.

Letters should normally be under 500 words in length, double-spaced throughout, signed by all authors and fully referenced. The edited version will be returned for approval before publication.

\section{BONE REGROWTH AFTER LAMINECTOMY}

Sir,

I write about the article by Postacchini and Cinotti entitled 'Bone regrowth after surgical decompression for lumbar spinal stenosis', published in your November 1992 issue (1992; 74-B:862-9).

Their paper was previously presented at the 1991 European Spine Society Meeting in Rome at which time I gave Dr Postacchini a report of the paper by myself and $M$. Ortolani entitled 'Evoluzione del processo riparativo dell'arco vertebrale dopo laminectomia e conseguenze statiche a distanza in operati per ernia discale' published in La Clinica Ortopedica (Padova) 1967; 19:600-12. The fact that our radiological and histological studies described bone regrowth after laminectomy for lumbar disc herniation is hardly an adequate reason for making no reference to our work. It is a duty to quote the relevant works of previous authors. In this case the omission seems to have been deliberate and I therefore ask you to publish this letter in the cause of scientific objectivity.

\section{R. SCAPINELLI, MD \\ Clinica Ortopedica III \\ Università di Padova \\ Padova, Italy.}

Postacchini F, Cinotti G. Bone regrowth after surgical decompression for lumbar spinal stenosis. J Bone Joint Surg [Br] 1992; 74-B:862-9.

Scapinelli R, Ortolani M. Evoluzione del processo riparativo dell'arco vertebralc dopo laminectomia e conseguenze statiche a distanza in operati per ernia discale. La Clinica Ortopedica (Padova) 1967; 19:600-12.

\section{Authors' reply:}

Sir

We were aware of the paper by Scapinelli and Ortolani on regrowth of the posterior vertebral arch after operation for disc herniation, but we were concerned only with patients suffering from spinal stenosis. In such cases, bone regrowth is markedly affected by the narrowness of the vertebral canal and the tendency in these patients to develop hypertrophic change in the posterior joints. Our results confirmed these factors, and are completely different from the lack of regrowth shown by Scapinelli and Ortolani after total laminectomy. The comparison of radiographic changes in patients with different conditions, such as spinal stenosis and disc herniation, would be inappropriate and misleading.

Scapinelli and Ortolani were not the only authors to observe bone regrowth after surgery for disc herniation, just as we were not

(01994 British Editorial Society of Bone and Joint Surgery $0301-620 X / 94 / 1746 \$ 2.00$

J Bone Joint Surg /Br] 1994; 76-B:163-6. the first to study this in stenotic patients. We aimed to determine the incidence and clinical implications of the regrowth of the posterior vertebral arch in patients treated for spinal stenosis. These issues were not mentioned by Scapinelli and Ortolani.

We strongly believe that it is a duty to quote relevant work of previous authors. When scientific contributions are becoming ever more numerous, however, they should be as concise as possible, limited to the problem under study and quoting only the pertinent literature.

\section{F. POSTACCHINI \\ University of Modena \\ Modena, Italy. \\ G. CINOTTI \\ University of Rome \\ Rome, Italy.}

\section{FRACTURES OF THE CALCANEUM}

Sir,

I was interested by the editorial and two articles on fractures of the calcaneum in the March 1993 issue (1993; 75-B:176-7, 183-8, 18995). Some facts about these fractures are not in question. The first is that they include a spectrum of bone and soft-tissue injuries. The second is that in some cases the bony architecture can be restored to close to normal. The third point is that modern techniques have minimised the complications of this surgery.

I do not agree, however, with the thrust of the editorial, which suggests that "better, quicker functional results" can be obtained by operation. This is not yet proven: early results from current trials suggest that there is little if any difference in outcome between operative and non-operative treatment. It would be unfortunate if orthopaedic surgeons rushed to operate on fractures of the calcaneum before the final results are available of these randomised prospective trials. Complete or near-complete restoration of bony architecture by surgery cannot guarantee improved healing of major soft-tissue injuries or damage to joint surfaces.

Orthopaedic surgeons (and their patients) would do well to await the results of properly conducted scientific studies before they change their existing practice for the management of these difficult fractures.

G. HORNE

Department of Surgery

Wellington School of Medicine

Wellington, New Zealand.

Eastwood DM, Gregg PJ, Atkins RM. Intra-articular fractures of the calcaneum. Part I: Pathological anatomy and classification. $J$ Bone Joint Surg [Br] 1993; 75-B:183-8.

Eastwood DM, Langkamer VG, Atkins RM. Intra-articular fractures of the calcaneum. Part II: Open reduction and internal fixation by the extended lateral transcalcaneal approach.J Bone Joint Surg $[\mathrm{Br}]$ 1993; 75-B:189-95

Kenwright J. Editorial. Fractures of the calcaneum.J Bone Joint Surg /Br] 1993; 75-B:176-7.

Author's reply:

Sir,

Geoffrey Horne puts forward three facts which are now "not in question". The second and third relate to the present possibility of restoring the bony architecture without major complications. This is a recently accepted advance in knowledge.

I also agree that one treatment method cannot be proved to be 